REVISTA DE ESTUDIOS BRASILEÑOS

e-ISSN: 2386-4540

https://doi.org/10.14201/

reb20196125565

AUTOR

Consuelo Díaz

Muñoz

consuelodiazm@

gmail.com

* Máster en Arte,

Pensamiento y Cultura

latinoamericanos por

el Instituto de Estudios

Avanzados de la

Universidad de Santiago

(Santiago de Chile,

Chile)

\section{Cuerpo, resistencia y género: un análisis del testimonio de María Amélia de Almeida desde la teoría género}

\author{
Corpo, resistência e gênero: uma análise do testemunho \\ de María Amélia de Almeida da teoria do gênero \\ Body, resistance and gender: an analysis of the testimony \\ of María Amélia de Almeida from the gender theory
}

\section{RESUMEN:}

Este artículo forma parte de una investigación mayor cuyo objetivo es interpretar los testimonios de prisión política latinoamericana de mujeres desde la teoría feminista para establecer nuevos parámetros para la comprensión y configuración de la mujer en la historia en tanto sujeto político y social activo. En este caso se analizará el testimonio de la brasileña Maria Amélia de Almeida, entendiendo este texto como un espacio de enunciación válido de una experiencia límite, construido a partir del intercambio de vivencias subjetivas que reafirmarán a la mujer como un sujeto político inserta en un contexto de presidio, violencia y transgresión. Así, esta sobreviviente expondrá cómo el género, al ser una estructura social, construye relaciones desiguales y legitima diferencias no solo en la participación política del propio partido, sino también, y sobre todo, en la represión padecida, enfocándose en cómo la dimensión sicológica de las torturas sexuales también adquiere un particular carácter de género.

\section{RESUMO:}

Este artigo é parte de uma pesquisa mais ampla, cujo objetivo é interpretar os depoimentos e testemunhos de prisão política de mulheres latino-americanas, utilizando a teoria feminista para estabelecer novos parâmetros para a compreensão e configuração da mulher na história enquanto sujeito sócio-político ativo. Nesse caso, o testemunho da brasileira Maria Amélia de Almeida será analisado, entendido como um espaço de enunciação válida de uma experiência limite, construída a partir da troca de vivências subjetivas, capazes de reafirmarem a mulher como sujeito político, inserido num contexto de prisão, violência e transgressão. Assim, a sobrevivente explicará como o gênero, enquanto estrutura social, constrói relações desiguais e legitima as diferenças, não apenas na participação política do próprio partido, mas também, e acima de tudo, na repressão sofrida, com foco na maneira pela qual a dimensão psicológica das torturas sexuais também adquire um caráter particular de gênero.

\footnotetext{
ABSTRACT:

This article is part of a wider investigation whose objective is to interpret the testimonies of the Latin American political prison of women from a feminist theory to establish new parameters for an understanding and configuration of women as active political and social subjects in history. In this case, I will analyze the testimony of Maria Amélia de Almeida from Brazil, understanding this text as a valid space of declaration of a to the limit-experience, originated from the exchange of subjective experiences that will reaffirm this woman as a political subject placed in a context of a prison, violence and transgression. Thus, this survivor will expose how gender, being a social structure, builds unequal relationships and legitimizes differences, not only in the political participation of the party itself, but also -and above all- in the repression suffered, where we will be focusing on how the psychological dimension of sexual tortures also acquire a particular gender character.
} 


\section{Consideraciones generales}

PALABRAS CLAVE

Dictadura;

tortura;

testimonio;

Durante la dictadura brasileña (1964-1985), al igual que en otros tiempos, las mujeres eran consideradas un objeto decorativo en las imágenes públicas de los dictadores y altos mandos, eran utilizadas para apoyar la figura del patriarca a partir de su rol maternal y doméstico (Camana, 2012). Sin embargo, desde aquella realidad en la que estaban sumergidas en el país, las mujeres constituyeron un segmento de la población que mostró cambios en sus relaciones con el trabajo, la familia, parejas y, por supuesto, con la política (De Alemida, 2015). Es desde estas redes donde se comienza a reactivar el movimiento feminista.

La unidad del movimiento feminista en Brasil permaneció activa hasta mediados de los años 1980, cuando la lucha opositora aún era un elemento aglutinador (Sarti, 1998), pues, llegada la democracia, este movimiento social fue perdiendo potencia a medida que los objetivos se iban diversificando debido a las múltiples fragmentaciones sociales que trajo consigo la dictadura. Otro elemento relevante dentro de este panorama es la valoración social que tenía el feminismo durante esta época: poseía una connotación peyorativa desde cualquier ángulo, pues para la derecha se trataba de un movimiento inmoral y, por lo tanto, peligroso; al mismo tiempo, para la izquierda el feminismo representaba un reformismo burgués (Sarti, 1998; Camana, 2012). En ese sentido, el género, al ser una estructura social, construye relaciones desiguales y legitima las diferencias en la participación política (De Almeida, 2015), lo que podemos ver reflejado de manera más cruda durante la represión en las dictaduras latinoamericanas.

teoría feminista.

PALAVRAS-CHAVE

Ditadura;

tortura;

testemunho;

teoria feminista.

KEYWORDS

Dictatorship: torture;

testimony;

feminist theory.

Recibido:

$23 / 04 / 2018$

Aceptado:

$26 / 04 / 2019$

Es posible apreciar y analizar esta problemática en los testimonios de prisión política producidos por mujeres. Este tipo de texto ha sido trabajado mayoritariamente desde el análisis literario e histórico. En este caso, se plantea una lectura bajo el prisma del género y la teoría feminista, considerando el estudio de la enunciación de las torturas sexuales y cómo aquella dimensión sicológica adquiere un carácter de género. Para ello se considera cómo la identidad femenina pasa a entenderse como un objeto sexual en la represión: "Todos los informes existentes sobre la tortura indican que el cuerpo femenino siempre fue un objeto 'especial' para los torturadores. El tratamiento de las mujeres incluía siempre una alta dosis de violencia sexual” (Jelin, 2002, p. 3). Si bien dentro de la militancia política y revolucionaria era posible observar esta transformación de la mujer, en el caso de la prisión política y tortura es posible advertir cómo las marcas de la violencia repercuten en los roles de género. Esto puede dilucidarse a partir de los testimonios y entrevistas de mujeres que fueron apresadas y torturadas.

Las militantes prisioneras eran tratadas de forma vejatoria. La humillación, la tortura y la violencia sexual eran un suplicio transversal a las prisioneras brasileñas (y latinoamericanas) reprimidas por los aparatos estatales. Según el capítulo sobre violencia sexual y de género del Informe de la Comisión Nacional de la Verdad de Brasil, de 2014, es posible identificar que este tipo de abusos no solo eran infringidos directamente contra los cuerpos de las mujeres, sino también a través de sus hijos, quienes eran expuestos a las torturas de sus padres e, incluso, recibían golpes y malos tratos. En este sentido, el testimonio de Maria Amélia refleja el sufrimiento al que fueron sometidos los cuerpos de las mujeres. Asimismo, gracias a esta declaración también es posible observar cómo el ejercicio de la violencia hacia las mujeres significaba un claro ejercicio de poder: una forma de castigo o venganza por transgredir las estructuras sociales de género.

\section{Resistir y denunciar}

Maria Amélia de Almeida Teles (1944) es una política e investigadora académica, exmilitante del Partido Comunista de Brasil (PCdoB). Trabajaba como profesora de Artes cuando fue detenida, 
el 28 de diciembre de 1972, en São Paulo, junto a su compañero, a sus dos hijos: Janaína ${ }^{1}$ (de 5 años) y Edson (de 4 años), y a su hermana, Crimea, quien estaba en la etapa final del embarazo. Afortunadamente, todos sobrevivieron y se dedicaron a denunciar tanto las torturas ocurridas en su detención, como las muertes y desapariciones de las que fueron testigos.

Este testimonio ocurre de manera oral en el contexto de la $25^{\mathrm{a}}$ Audiencia de la Comisión de la Verdad del Estado de São Paulo "Rubens Paiva", el 25 de marzo de 2013; es decir, 28 años después de terminada la dictadura brasileña se compone esta asamblea de testimoniantes. Maria Amélia de Almeida cuenta su experiencia junto a otras expositoras, por lo que este texto está compuesto por numerosos párrafos, destacando el nombre de quien emite cada intervención. No obstante, lo mencionado en las declaraciones ha sido previamente trabajado por sus protagonistas, por lo que no se trata de una relatoría improvisada, sino de un discurso pensado y elaborado particularmente para esta asamblea dedicada al tema de verdad y género. Es importante recalcar que Maria Amélia de Almeida se ha especializado en esta área, dedicando gran parte de su investigación a la problemática de la violencia sexual en las torturas infringidas durante la dictadura brasileña, así como a trabajar junto a familiares de detenidos desaparecidos. Por estas acciones recibió el Premio Nacional de Derechos Humanos, en 2008.

El presidente de la mesa de esta comisión fue el diputado por el Partido de los Trabajadores (PT) Adriano Diogo, quien, al iniciar la asamblea, destaca la relevancia de la temática de la verdad y de género, que pretende abordar aquella audiencia como tema central. Es así como le cede la palabra a la primera testimoniante: María Amélia. Ella comienza enfatizando la importancia de mostrar cómo la dictadura violentó, particularmente, a las mujeres, es decir, plantea su testimonio desde la perspectiva de la teoría feminista, cuestionando cómo las estructuras sociales configuradoras de roles de género también se encargan de amplificar la degradación específica que sufren las mujeres en el contexto de la prisión política. Antes de continuar su testimonio, Maria Amélia realiza una especie de paréntesis en el que explica por qué ella se percibe como presa política:

Eu acho que, eu sou uma presa política também, fui torturada junto com toda minha família, sou testemunha ocular de um assassinato de um dirigente comunista, Carlos Nicolau Danielli, sou testemunha também de um desaparecimento, que é o caso do Edgar Aquino Duarte. Tive meu companheiro preso, que nas primeiras horas da tortura entrou em estado de coma. Tive minha irmã presa grávida sendo torturada. Meu sobrinho sofreu essa tortura antes mesmo de nascer. Tive meus filhos sequestrados e levados para a sala de tortura na Operação Bandeirantes (Almeida, 2013, p. 2).

Es necesario poner atención a la construcción de este fragmento, pues predomina una autoafirmación del "yo", es decir, se expone una clara consciencia sobre las condiciones vivenciadas y padecidas en tanto sujeto político no reconocido en su diferencia de género. Es así como empieza enunciando: "Yo creo que también soy una presa política...", marcando el uso de verbos en primera persona a lo largo del párrafo: "soy", "fui", "tuve". Todos estos verbos son utilizados para vincularse a las otras víctimas de tortura con las que estuvo en el mismo centro de detención, de ahí que mencione que fue violentada con toda su familia, que fue testigo ocular de un asesinato y de una desaparición, que tuvo a su compañero preso y en coma, que tuvo a su hermana, embarazada, presa y torturada, y a sus hijos secuestrados. El formato que adopta esta primera parte del testimonio parece ser una justificación del porqué ella se entiende a sí misma como prisionera política, por eso no comienza con una afirmación absoluta, por ejemplo, (Yo "soy" una prisionera política) sino con un supuesto (Yo "creo" que soy una presa política también), seguido de una serie de asociaciones que funcionan a modo explicativo de aquel postulado.

Asimismo, también es relevante la mención inmediata de dos nombres de presos políticos asesinados y desaparecidos, ya que si bien el testimonio se dedica a relatar una verdad personal en que la narradora es protagonista, igualmente se configura un espacio dedicado a la denuncia en el que se vuelve imperativo hacer mención del otro ausente, pues eso también constituye parte de la experiencia de prisión de la 
testimoniante, considerando lo postulado por Jelin (2002) respecto a cómo la mujer relata sus vivencias en la clave más tradicional de su rol que es la de "vivir por otros", pues dentro de la construcción social de género la identidad femenina se define, entre otros aspectos, a partir del cuidado de otro cercano. Estos elementos propiamente "femeninos" resultan ser característicos en muchos de los testimonios de mujeres prisioneras, pues silencian el relato de su propia experiencia en pos de recordar y narrar la de un(a) otro(a) ausente, desplazando el hablar de la violencia, específicamente la sexual, padecida por ellas. Resulta un punto en común el hecho de que aquellas mujeres supervivientes se dediquen a priorizar, sobre sí mismas, el relato de lo ocurrido a quienes fueron asesinados y desaparecidos.

Así, es en el ejercicio de este rol "femenino" cuando se abre un espacio para hablar del otro, lo que se apreciará a lo largo del testimonio de Maria Amélia de Almeida, no solo a través de la mención de nombres sino también en la consideración que realiza sobre su hermana y sobrino no nato, por ejemplo, ya que al decir que esta fue torturada mientras estaba embarazada y que por ello su sobrino sufrió aquella violencia incluso antes de nacer, es en sí mismo una consideración por el otro que desplaza la experiencia personal en pos de contar la vivencia de un ser querido.

Integrando lo recién propuesto respecto a cómo esta testimoniante plantea sus experiencias desde la consideración de la teoría feminista, en tanto se dedica a indagar y problematizar cómo la estructuración social de los roles de género y la diferencia de los cuerpos femeninos también pasan a ser una herramienta de tortura, es pertinente considerar cada uno de los comentarios que realice respecto a ello:

Diante disso, tem 40 anos que esses fatos aconteceram comigo e eu falo com dificuldade dessa situação. Inclusive eu sofri uma violência, ou várias violências sexuais. Toda nossa tortura era feita nós nuas, as mulheres nuas (Almeida, 2013, p. 2).

Es importante la mención del tiempo que ha pasado desde aquellos eventos pues, a pesar de esto, relatar esas vivencias traumáticas continúa siendo complejo. La verbalización de la experiencia límite dificulta la configuración del testimonio; y es, precisamente, luego de este comentario cuando se introduce la mención de haber sido víctima de violencia sexual, parece, incluso, que se propone como una información anexa pues se expone de manera acotada y con dificultad de enunciación. No obstante, la narradora al decir que el tema le es complicado de hablar y luego enunciar de aquella manera el tipo de agresiones que padeció, complementa forma y fondo: dice concretamente que son hechos difíciles de relatar y aquello se refleja en la enunciación (en la oralidad que es transcrita y presentada al receptor en formato texto), al mencionar sin desarrollar para inmediatamente acoplar su propia experiencia a la de una multitud ("Toda nuestra tortura era hecha con nosotras desnudas, las mujeres desnudas"). Se posiciona como un ejemplo concreto del padecimiento de la violencia sexual, pero al ser una situación reiterativa se vuelve necesario incluir su propia experiencia con la de las demás y presentar aquellas transgresiones como una denuncia conjunta y no individual; y es que al considerar y mencionar que ese tipo de tratos era general y aplicado a la mayoría de las mujeres, se plantea una problemática de género necesaria de analizar y acusar. Así como Maria Amélia relata su experiencia traumática, también se encarga de aclarar que sus vivencias no fueron particulares y exclusivas, sino que estas se aplican también a lo experimentado por las demás militantes torturadas, pues se trata de medidas represivas aplicadas a todas las prisioneras políticas contrarias a la dictadura.

Otra forma de tortura utilizada por los organismos represores es involucrar a los seres queridos de los prisioneros. Considerando la particular preocupación por el otro como rol propio de la mujer (Jelin, 2002), especialmente por personas cercanas como familiares e hijos, la tortura mediante la presencia y abuso de hijos de las presidiarias significa utilizar una de las condiciones específicas de las mujeres, la maternidad, como una característica adicional para la tortura, ya que los agentes dictatoriales utilizan la condición femenina para intensificar el proceso de represión (Almeida, 2015): 
E meus filhos me viram dessa forma. Eu urinada, com fezes, com, enfim, o meu filho chegou para mim e disse, mãe, por que é que você ficou azul e o pai ficou verde? Porque o pai estava saindo do estado de coma e eu estava azul de tanto, aí que eu me dei conta, de tantos hematomas no meu corpo (Almeida, 2013, p. 2).

Como se mencionó anteriormente, Maria Amélia fue apresada junto a su compañero, hermana e hijos. Estos últimos fueron retenidos mientras sus padres eran torturados y cada cierto tiempo entraban a la sala para que vieran las condiciones en que se encontraba su madre y, a la vez, aprovechaban aquella instancia para amenazar a Maria Amélia con que sus hijos también serían torturados si no entregaba la información solicitada. Por eso, en la audiencia, Maria Amélia destaca que sus hijos la vieran de esa forma: orinada, con excrementos, golpeada; pues también constituye una técnica de tortura el exponer a los niños a ese nivel de violencia, sufriendo tanto los hijos como la madre vulnerada en su condición de mujer, cuya identidad está ligada al cuidado y preocupación por los otros (Jelin, 2002). Otro punto relevante de este fragmento es cómo la pregunta del hijo, Edson, respecto a los colores de los cuerpos de sus padres (“¿Por qué estás azul, por qué papá está verde?") detona el autoreconocimiento en Maria Amélia, pues recién en ese punto es capaz de darse cuenta de que su piel había adquirido tonalidades azules debido a los múltiples hematomas en su cuerpo y cómo su pareja había sido torturada hasta entrar en estado de coma, siendo esto la causa de su tono verdoso. Es así como la pregunta del niño se vuelve un referente de la realidad que lleva a la narradora a una afirmación del "yo" al entenderse como víctima de la represión, motivo por el cual en su relato menciona "ahí fue que me di cuenta", pues la interpelación de su hijo se vuelve clave para comprender la situación en la que estaban inmersos.

La forma en que este testimonio opera parece reflejar un patrón que consiste en relatar ciertos episodios para luego analizarlos o comentarlos desde la consideración de la problemática de género, pues esta Comisión de la Verdad del Estado de São Paulo "Rubens Paiva" tiene por objetivo no solo denunciar las prácticas transgresoras de los derechos humanos, sino también aclarar la particular forma de represión hacia las mujeres:

Em uma dessas sessões um torturador da Operação Bandeirantes, que tinha o nome de Mangabeira ou Gaeta, ele, eu amarrada na cadeira do dragão, ele se masturbando e jogando a porra em cima do meu corpo. Eu não gosto de falar disso, mas eu vejo a importância desse momento de tratar a verdade de gênero pensando nessas desigualdades entre homens e mulheres em que esses agentes do Estado, os repressores, usaram dessa desigualdade para nos torturar mais, de uma certa forma de usar essa condição nossa, nós fomos torturadas com violência sexual, usaram a maternidade contra nós, minha irmã acabou tendo o parto, tendo o filho na prisão (Almeida, 2013, p. 3).

Nuevamente la narradora reitera cómo hablar de aquellas experiencias límites, cómo el narrar la violencia sexual supone una tarea difícil de realizar. Es por ello que, en un comienzo, Maria Amélia menciona que, aunque hayan pasado cuarenta años de aquellos acontecimientos le resulta complejo hablar de eso y, en este fragmento, repite la dificultad que ello representa al decir "no me gusta hablar de eso". Y es que el conflicto de narrar lo irrepresentable surge desde lo cruento de una vivencia traumática como la tortura, particularmente la tortura sexual, ya que ésta, en cualquiera de sus formas, constituye una violación, es decir, una forma de sexo forzado impuesto por un individuo con poder de intimidación sobre otro, desencadenando un profundo sentimiento de terror y humillación (Segato, 2003). Todos los abusos sexuales representan un acto de poder y sometimiento que anula absolutamente el cuerpo de la víctima, avergonzándola y aterrorizándola, sin importar el tipo de abuso sexual cometido, pues éstos, en cualquiera de sus formas, significan una violación para la víctima en tanto trasgreden y humillan su cuerpo. Si bien Maria Amélia no narra una violación clásica, que incluya penetración, el hecho que mencione que su carcelero se masturbaba frente a su cuerpo desnudo, eyaculando sobre ella, también puede entenderse como una violación alegórica (Segato, 2003), ya que también se aprecia el forzamiento, la transgresión y el abuso de otro, elementos que son propios de la violación. Sin embargo, si bien no habría penetración en esta masturbación sobre la prisionera, sí está 
claramente presente la intención de abuso y manipulación indeseada del otro, pues la violación alegórica consideraría todo tipo de humillación y vejámenes perpetrados al otro cuerpo. Considerando esto, no sería necesario establecer una diferencia entre eyacular sobre una persona y violar, pues ambas constituirían una transgresión con repercusiones traumáticas para ella.

Estas son algunas de las razones por las que se vuelve tan complejo enunciar aquella experiencia. El horror de lo vivido limita el lenguaje para representarlo (Rancière, 2011), por eso Maria Amélia menciona que no le gusta hablar de eso pero que, aun así es capaz de identificar la importancia de hablar sobre la verdad y el género en ese momento, con ocasión de la audiencia, y recalcar en su denuncia cómo aquellas desigualdades entre hombres y mujeres fueron utilizadas por los represores para intensificar el proceso de tortura ${ }^{2}$. Los vejámenes cometidos a las prisioneras no solo poseen una relevancia operacional para obtener información para combatir a los grupos de oposición y resistencia al régimen, sino que también la tortura de mujeres se constituye como castigo y como una forma de venganza, desde la diferencia de género, contra una mujer que ha salido de su lugar, de su posición subordinada, acción que pone en entredicho la posición del hombre en la estructura social (Segato, 2003), que obedece a un status quo impuesto por el Estado que luego fue consolidado en la dictadura. Asimismo, se trata de una instancia de sanción por salir del lugar social y simbólico que ocupa la mujer.

Considerando esto, ella menciona de manera particular que los agentes del Estado utilizaban esa condición "nuestra" (la femenina) para reprimirlas, siendo un objeto "especial" para los torturadores (Jelin, 2002); es interesante el uso de la primera persona plural para referirse a las víctimas de la represión, ya que no se trataría, entonces, de un testimonio individual en el que se relaten y denuncien las experiencias personales, sino que se plantean las transgresiones y sufrimiento de una comunidad en tanto sujetos políticos femeninos que, debido a la tortura, han sido víctimas de un castigo o venganza ya que han salido de su posición subordinada (Segato, 2003). Es a partir de estas observaciones e inclusiones en el lenguaje lo que refleja el entender a las víctimas de tortura sexual no como casos aislados sino como hechos recurrentes, usuales y generales; siendo esta otra razón más para indagar en aquel tipo de denuncias y continuar investigando al respecto, contemplando de manera transversal una lectura desde la problemática de género, pues aquella es un punto esencial para comprender y contar la historia de las mujeres en la dictadura, lo que significaría, necesariamente, la redefinición y ampliación de las nociones tradicionales del significado histórico, ya que se consideraría la experiencia personal y subjetiva al igual que las actividades públicas y políticas (Scott, 1996), teniendo en cuenta que lo personal también es político (Kirkwood, 1986), pues ambos elementos están vinculados, por lo que es necesario tener presentes aquellos tipos de violencia específica hacia las mujeres.

Estas consideraciones continúan de forma permanente a lo largo del testimonio de María Amélia, precisando cómo el denunciar la violencia sexual también significa un proceso para las víctimas, pues aquel tipo de transgresiones representan abusos que deben ser redescubiertos por quienes los padecieron para poder hablar de ello ya que, en primera instancia, fueron silenciados principalmente por vergüenza y por el dolor que significa enfrentarse a esos recuerdos:

[E]u pude falar com as mulheres presas, trocar essas experiências, mas eu acho, a Leo ${ }^{3}$ pode falar melhor do que eu depois, mas eu acho que a violência sexual nós sempre omitimos. Era muito forte falar da violência sexual. Nós deixamos, nós mesmas, as sobreviventes, nós deixamos essa violência sexual como sendo algo mais secundário nas nossas vidas (Almeida, 2013, p. 3).

El hecho de mencionar las conversaciones en prisión con las demás mujeres torturadas refuerza aquella idea del sufrimiento padecido por una comunidad de mujeres autoreconocidas como sujetos políticos. Esta es, precisamente, la razón de su castigo, y también forma parte de la configuración del pensamiento feminista (cuya problematización e investigación conlleva a la formación en proceso de una teoría feminista) ya que este entiende como una de sus bases el compartir vivencias con otras mujeres a través del diálogo $\mathrm{y}$, en ese proceso, de comunicar experiencias subjetivas, es cuando se alcanza un nivel de consciencia 
superior que desencadena la politización y autoreconocimiento de los sujetos (Nicholson, 1997). Mediante este intercambio de subjetividades, Maria Amélia es capaz de concluir que las temáticas referentes al abuso sexual resultaban omitidas o desplazadas, pues era "muy fuerte" hablar sobre violencia sexual, por lo que aquella comunidad de mujeres relegó a un segundo plano ese tipo de temas dejándolo como algo secundario en sus vidas. Esto puede entenderse a partir de lo propuesto por Jelin (2002), respecto a cómo las mujeres víctimas de violencia sexual sienten vergüenza de hablar sobre aquellas experiencias debido a la magnitud del horror y humillación (Segato, 2003). Por otro lado, el hecho de ser capaces de conversarlo entre ellas y, además, testimoniar en pos de denunciar y acusar aquellas prácticas también significa el reconocimiento de esos cuerpos resilientes capaces de reclamar la voz para decir lo inefable, pues el hecho de relatar la experiencia traumática resulta beneficioso en términos de procesar la experiencia (Sutton, 2014).

A partir de lo enunciado y lo callado de aquellas vivencias límites es posible continuar identificando ciertos patrones del testimonio de mujeres, como el ya mencionado "vivir por otros" de Jelin (2002), que prioriza el relato sobre otros antes que el personal y, sin embargo, a través de la narración de la vivencia de estos otros (generalmente seres queridos y familiares) es donde puede apreciarse cómo se cuelan las experiencias personales:

[N]ós priorizamos falar da violência contra as crianças, das torturas que nós sofremos enquanto militantes políticos, sem dar especificidade a nossa condição de mulher. Nós falamos dos assassinatos que nós presenciamos. Sempre nós denunciamos, o caso do assassinato do Carlos Nicolau Danielli, nós nunca deixamos de denunciar, e nós, eu acho que é um peso muito grande falar da violência sexual, você fica muito estigmatizada, você quase que é secundarizada mesmo ou é dado um descrédito, isso não é tão importante assim. Eu acho que foi assim que nós vimos esse tempo todo (...) e nessas graves violações de direitos humanos não pode deixar de considerar a violência às violações dos direitos humanos das mulheres, a violência praticada contra as mulheres (Almeida, 2013, p. 3).

Al hablar sobre las torturas sufridas en prisión, las mujeres priorizan el hablar sobre la violencia contra sus hijos o las transgresiones sufridas como militantes políticos en general, sin contemplar la especificidad de su condición de mujeres. El relato personal se vuelca en las vivencias de los otros ausentes o de quien no puede expresarse (como los niños). Prefieren denunciar constantemente los asesinatos y desapariciones de las que fueron testigos, pues hablar sobre la violencia sexual específica padecida de forma personal significa "un peso muy grande" ya que estigmatiza a la víctima no solo en el momento exacto de padecerla sino también en el posterior a ello: denunciar la violencia sexual significa someterse al escarnio público, es denudarse ante la sociedad ${ }^{4}$. Sin embargo, parece que Maria Amélia también relaciona este silencio respecto a la violencia sexual al afán de la mujer por ponerse en un lugar secundario desacreditando sus propias experiencias y subjetividades. Tal vez este rol del "vivir por otros" que desplaza la vivencia personal en pos del relato del otro ausente, se acople y potencie con la vergüenza y dificultad que representa hablar de la violencia sexual padecida. No obstante, es posible abordar aquellos temas cuarenta años después, en el contexto de la audiencia, por lo que es posible proponer que la distancia temporal permite la abstracción de esos recuerdos, aglutinando los episodios y conversaciones para llegar a nuevas conclusiones necesarias de denunciar. Al final de este fragmento, Maria Amélia menciona nuevamente la relevancia de considerar esas graves violaciones a los derechos humanos de las mujeres y la violencia específica empleada contra ellas.

El destacar la importancia de la memoria desde la problemática de género significa visibilizar una mirada desde otro ángulo, brindando la posibilidad de un nuevo análisis interpretativo de un episodio traumático como la dictadura militar. Para esto se vuelve necesario no solo mencionar y destacar cada una de las formas en cómo las diferencias entre hombres y mujeres agudizaron los procesos represivos, sino también verbalizar para hacer presente a las mujeres que fueron asesinadas por no obedecer el rol que les estaba socialmente destinado: 
[E] não esquecer que dentre esses mortos e desaparecidos políticos há 50 mulheres e essas 50 mulheres eu queria estar nomeando uma com uma para que a gente firmasse aqui, coletivamente esse compromisso de buscar esclarecer, localizar e dar um lugar justo a essas mulheres, porque a história tem sido bastante injusta ainda com as mulheres. Então eu queria estar falando disso. Eu tinha 27 anos, hoje eu tenho 68 anos, mas eu tenho: Alceri Maria Gomes da Silva, era da Vanguarda Popular Revolucionária, foi assassinada em São Paulo em 1970. Ana Maria Nacinovic Corrêa, ALN, foi morta em 1972 em São Paulo. Ana Rosa Kucinski Silva, Ação Libertadora Nacional, desaparecida em São Paulo em 1974.... (Almeida, 2013, p. 4).

La testimoniante recalca la importancia de reconocer que dentro de los numerosos detenidos desparecidos de la dictadura brasileña hay cincuenta mujeres reconocidas, y al estar relatando su experiencia plural, pues Maria Amélia no narra constantemente desde un "yo" sino de un "nosotras", dentro de una comisión sobre género y verdad, se vuelve necesario nombrar a cada una de esas mujeres asesinadas y desaparecidas, pues la historia ya ha "sido bastante injusta" con los sujetos femeninos en general, por eso, como una nueva demostración de la afirmación del "yo", del "nosotras", Maria Amélia decide nombrar, una por una, a las compañeras muertas a manos de los agentes represores del Estado. Así, menciona cada uno de los nombres, agrupaciones políticas a las que pertenecían y año de muerte o desaparición de estas mujeres. Es relevante el hecho de mencionar lo injusta que ha sido la historia con las mujeres, pues es una crítica a la historia oficial, la que se construye desde y por la institución; tratándose de una crítica realizada, precisamente, en un espacio institucional como una audiencia pública legislativa en la que está declarando su testimonio. Es decir, criticar la historia oficial, institucional, desde una misma institución constituye en sí mismo un acto político, tal y como la opción de replantear la historia desde la consideración de las mujeres, pues la manera en que se conserva la memoria de la mujer es también "una forma de activismo político" (Hirsch \& Smith, 2002, p. 12). Es así como el hecho de nombrar a cada una de las mujeres asesinadas por la dictadura militar brasileña plantea, a su vez, la intención de una nueva investigación histórica que propone romper la noción de fijeza y descubrir la represión que conduce a la aparición de una permanencia intemporal en la representación binara del género (Scott, 1996), siendo esta invariabilidad de lo binario las diferencias que constituyen a hombres y mujeres, las mismas desigualdades utilizadas por los organismos represivos para torturar a los cuerpos femeninos.

Continuando la premisa de recordar y nombrar a aquellas compañeras asesinadas por la represión, o bien, hablar por quienes no pueden, Maria Amélia, al final de su intervención testimonial, considera imperativo hacer mención y reconocimiento a Inês Etienne Romeu (1942 - 2015), ya que ella, por problemas de salud resultado de un ataque, no pudo asistir y dar su valioso testimonio a la Comisión:

Eu queria só explicar o seguinte, a Inês Etienne, essa companheira que está sendo homenageada hoje e que deve ser sempre lembrada, ela fez essa denúncia em 1979, quer dizer já tem mais de 30 anos, mas em 2003 aconteceu um acidente (...) ela foi encontrada caída dentro da sala com a cabeça rachada, chegou até a perder um pouco da massa encefálica (...) tudo indica, parece que alguém atacou a Inês (...) A Inês falava, quem conviveu com ela como nós convivemos ela falava que tinha pessoas da repressão que ameaçavam sua vida, ela falava que era perseguida (Almeida, 2013, pp. 27-28).

Esta asamblea además de tener como objetivo la temática de la verdad y del género, también pretende homenajear a Inês Etienne por su potente testimonio y acusación de la ubicación de la Casa de la Muerte, denuncia hecha hace más de treinta años. A partir de esto, Maria Amélia reitera la importancia de recordar este acto de Etienne Romeu y, además, se encarga de denunciar el hecho de por qué no pudo estar presente en la audiencia. En 2003, Inês sufrió un atentado, la golpearon en la cabeza por lo que perdió masa encefálica, dejándola inconsciente. Aquello repercutió gravemente en su salud, por lo que se vio forzada a disminuir su participación en contextos de denuncia y defensa de derechos humanos. Quien convivió con Etienne, como sus cercanos lo hicieron, sabían que ella era perseguida y amenazada de muerte por exagentes represivos. Maria Amélia recurre a la especificación de su cercanía con Etienne Romeu para aclarar y demostrar el 
vínculo compartido entre exprisioneras políticas, por lo que ellas pueden comprender a Inês mejor que otras personas que no vivieron aquellas experiencias. El hecho de denunciar el ataque en el espacio de la Comisión de la Verdad del Estado de São Paulo "Rubens Paiva" adquiere una particular relevancia, pues se recalca la amenaza de una represión latente, constante, además de plantear, implícitamente, la vigencia de la problemática de la memoria, el olvido y el silencio: Inês se instala como una amenaza para el fantasma del régimen militar, por lo que debe ser acallada.

De esta forma, se plantea la necesidad de la conservación de la memoria a partir de la denuncia y el valor del testimonio, pues la memoria no se opone al olvido, sino que son el olvido y la conservación los términos que contrastan (cómo mantener el recuerdo, cómo perdura, qué perdura), pues la memoria es una forma de interacción entre ambos conceptos (Todorov, 2013). Así, ¿cómo surge y se concreta la importancia del testimonio? Este actúa como una de las formas de conservar la memoria, por lo que el hecho de atentar contra la vida de Inês, en democracia, constituye un atentado no solo contra la integridad de un sujeto político, sino también contra la preservación de la historia de un país. Asimismo, la denuncia hecha por Maria Amélia en este contexto extrajudicial también propone una permanente violencia hacia la mujer, siendo un mal vigente y perpetuo que no ha podido ser desarticulado, pues responde a las construcciones sociales de género donde el sujeto femenino no es reconocido en su diferencia y, por ello, es subordinada a lo masculino.

Para concluir su testimonio, Maria Amélia realiza una reflexión final en torno a Inês Etienne Romeu y la relevancia de su valor al denunciar. Nuevamente, es posible apreciar cómo el relato de las experiencias personales se desplaza para relatar la vivencia de otros (Jelin, 2002) (otra, en este caso), que no pueden estar presentes por diferentes circunstancias. Así, las subjetividades de la testimoniante se cuelan en la narración sobre un otro ausente. $Y$ es través de las reflexiones que plantea Maria Amélia que se puede identificar en su discurso la necesidad de implementar el pensamiento feminista al momento de plantear las vivencias e historias de las mujeres:

A Inês foi extremamente corajosa. Quando ela denunciou a Casa da Morte lá em Petrópolis, que é uma casa e que nessa casa, pelo que depois nós ficamos sabendo, os presos e as presas políticas iam lá para ser mortos. Ninguém saiu de lá vivo. E a Inês, por uma questão de, enfim, não sei por qual razão, a Inês é a única que saiu viva. A única que saiu viva e que deu este depoimento, teve essa coragem. Porque ela, mais do que ninguém, sabia o preço que ela ia pagar e que ela tem e que custado um preço muito alto para ela essa denúncia, viu gente. Tem custado muito alto. Agora nós entendemos assim, que trazer a verdade e gênero aqui na Comissão Nacional, aqui na Comissão Estadual e aqui no Brasil inteiro tem que partir, tem que trazer a experiência da Inês Etienne, para a gente estar investigando, estar sendo estimulados todos nós a investigar o que aconteceu (Almeida, 2013, p. 28).

Maria Amélia destaca, nuevamente, el valor (lo "corajosa") de Inês al denunciar los horrores a los que fue sometida, pues todos los que ingresaban en la Casa de la Muerte eran asesinados, los prisioneros eran llevados allá para matarlos, ninguno salió vivo menos Inês Etienne, por razones que aún nadie clarifica. Por esto, ella más que ningún otro sabía el alto precio que iba a tener que pagar por su denuncia, por su testimonio, pues había sido testigo de todo lo que podían ser capaces los agentes represivos y, aun así, decide vivir para poder contar lo que experimentó en ese lugar. Por eso, Maria Amélia recurre constantemente a plantear la relevancia de la experiencia de Inês a la Comisión, ya que plasmar aquella vivencia en ese contexto público significa estimular a la población para que investigue lo que sucedió, proponiendo la conservación de la memoria no solo por parte de quienes testimonian, sino también por los receptores. En la medida en que Maria Amélia va exponiendo los acontecimientos ocurridos a Inês, va planteando implícitamente su propia subjetividad: la búsqueda por concretar una mirada de género para leer y contar las experiencias de las mujeres. 


\section{NOTAS}

1 Janaína de Almeida Teles (1967) es una historiadora que ha dedicado su investigación a detenidos, torturas y violencia de género durante la dictadura brasileña, tomando como caso particular el de su madre y el de ella, considerando que, con cinco años, fue una de las prisioneras políticas más pequeñas.

2 En 2015, Maria Amélia de Almeida publica un artículo académico en el que se dedica a indagar y analizar, precisamente, esta problemática. Lo que significa que el testimonio en la comisión del 2013 no quedó solamente en la denuncia, sino que fue un detonante para investigar y continuar problematizando en torno a la violencia sexual contra las mujeres en dictadura.

3 Se refiere a Eleonora Menicucci (1944), socióloga y feminista brasileña, detenida y torturada en la dictadura. Ella también está presente, junto a Maria Amélia, en la Comisión de la Verdad del Estado de São Paulo "Rubens Paiva".

4 Esta idea de hablar sobre la violencia sexual y desnudarse, es propuesta por Eleonora Menicucci en la misma instancia de la Comisión de la Verdad del Estado de São Paulo "Rubens Paiva" junto a Maria Amélia de Almeida.

\section{REFERENCIAS BIBLIOGRÁFICAS}

Almeida Teles, A de. (2013). Relatório depoimento. Comissão da verdade. São Paulo: BK Consultoria e Serviços LTDA.

Almeida Teles, A de. (2015). Construcción de la memoria y la verdad en una perspectiva de género. GV Law Journal, 11(2), São Paulo.

Almeida, J. (2011). Memórias dos cárceres da ditadura: os testemunhos e as lutas dos presos políticos no Brasil. São Paulo: Universidad de São Paulo.

Camana, Á. (2012). A representação da mulher durante a ditadura militar brasileira. Anúncios da revista Veja 19691985. Porto Alegre.

Comissão Nacional da Verdade do Brasil. (2014). Violência sexual, violência de gênero e violência contra crianças e adolescentes. Relatório da Comissão Nacional da Verdade do Brasil (Vol. I, Parte 3, Cap. 10). Brasilia. Disponible en [http://cnv.memoriasreveladas.gov.br/ images/documentos/Capitulo10/Capitulo\%2010.pdf].

Forcinito, A. (2003). Cuerpos y traiciones: violencia doméstica, violencia estatal y derechos humanos. Revista de Investigaciones Literarias y Culturales, $\mathrm{n}^{\circ}$ 20/21, 51-64.

Hirsch, M. \& Smith, V. (2002). Feminism and Cultural Memory: An Introduction. Signs, 25(1), University of Chicago.

Jelin, E. (2002). Los trabajos de la memoria. Madrid: Siglo Veintiuno Ed.

Kirkwood, J. (1986). Ser política en Chile: las feministas y los partidos. Santiago de Chile: LOM.

Menicucci, E. (2013). Relatório depoimento. Comissão da verdade. São Paulo: BK Consultoria e Serviços LTDA.

Nicholson, L. (1997). Introduction. En L. Nicholson (Org.). The second wave. A reader in feminist theory. Nueva York: Routledge.

Rancière, J. (2011). Si existe lo irrepresentable. En J. Rancière (Org.). El destino de las imágenes. Buenos Aires: Prometeo Libros.

Sarti, C. (1998). O início do feminismo sob a ditadura no Brasil: o que ficou escondido. São Paulo.

Scott, J. (1996). El género: una categoría útil para el análisis histórico. En M. Lamas (Comp.). El género, la construcción social de la diferencia sexual (2013). Ciudad de México: Universidad Nacional Autónoma de México.

Segato, R. (2003). Estructuras elementales de la violencia. Buenos Aires: Universidad Nacional de Quilmes Editorial. 
- CUERPO, RESISTENCIA Y GÉNERO: UN ANÁLISIS DEL TESTIMONIO

DE MARÍA AMÉLIA DE ALMEIDA DESDE LA TEORÍA GÉNERO •

CONSUELO DÍAZ MUÑOZ

Sutton, B. (2015). Terror, testimonio, y transmisión: Voces de mujeres sobrevivientes de centros clandestinos de detención en Argentina (1976-1983). Mora, 21, 2-23.

Todorov, T. (2013) Los usos de la memoria. Santiago de Chile, Museo de la Memoria y Derechos Humanos. 